\title{
Comparative study between radiobasilic and brachiobasilic arteriovenous fistula
}

\author{
Mohamed A El-Heniedy \\ Department of Vascular Surgery,Tanta University, Tanta, Egypt.
}

\section{Correspondence:}

Mohamed A El-Heniedy, Assistant Professor of Vascular Surgery, Tanta University, Egypt. E-mail: hin1964@yahoo.com

\begin{abstract}
As dialysis population becomes older, the need for secondary and tertiary access will grow. This study was done in Tanta University Hospitals from January 1, 2008 to December 31, 2010 to compare outcome, and complication rates of radiobasilic arteriovenous fistula (RBAVF) versus brachiobasilic AVF (BBAVF). Out of 512 patients with chronic renal failure $(C R F)$ the basilic vein was the only available one in 97 patients. RBAVF in the forearm was done in 20 cases (group1) while, BBAVF in the arm was done in 70 patients (group2). The immediate patency rate was $95 \%$ in groupl Vs $92.8 \%$ in group2. Primary 1-year patency was $75 \% \pm 6.43$ Vs $70.14 \% \pm 8.94$ (P 0.663) in groupl and group2 respectively. There was significant low postoperative complication rate in groupl than in group2 (25\% Vs 67\% P 0.007). RBAVF represents an important option for vascular access and excellent comparable patency and should be considered when the basilic vein is the only available suitable vein.
\end{abstract}

\section{Introduction:}

Autologous arteriovenous fistula (AVF) has been the "gold standard" for patients needing hemodialysis in the past 30 years. ${ }^{1}$ During the past decade, increasing prevalence of patients requiring hemodialysis has resulted in dialysis access procedures becoming some of the most common operations performed by vascular surgeons. ${ }^{2,3}$

The national kidney foundation dialysis outcomes quality initiative (NKF-DOQI) guidelines that were created in 1997 and updated in 2000 and 2006, recommend that the order of preference for placement is the radial-cephalic primary AVF, followed by the secondary brachiocephalic and, if either of these is not available, a transposed brachial basilic or an arteriovenous graft (polytetrafluoroethylene; PTFE) AVF should be fashioned. However, the transposed radial basilic vein AVF in the forearm was not mentioned by these guidelines. ${ }^{4-6}$
It is well-established that AVF exhibit superior long-term function compared with prosthetic grafts (AVG). ${ }^{7-10}$ Furthermore, AVF result in fewer infection rate and ischemic complications compared with AVG. ${ }^{11-13}$ The 1-year complication rate of a primary AVG for haemodialysis ranges from $33 \%$ to $99 \% .14$ It was found that the use of prosthetic forearm loop grafts, in particular, has resulted in the loss of the basilic vein as an autologous conduit from subsequent graft revisions advancing towards the axillary vein.

The basilic vein offers many advantages over the other arm veins. First, the basilic vein remains hidden and relatively unused owing to its deep position on the medial side of the upper arm. This prevents routine vein puncture, with the attendant scarring and superficial thrombophlebitis. Second, the basilic vein is the largest superficial vein in the arm, often reaching $10 \mathrm{~mm}$ or more in maximum diameter. This size allows rapid maturation and relatively easy cannulation. However, suitable basilic 
vein may not always be found in the forearm region (below the elbow). ${ }^{15}$ The expanding haemodialysis population has lead to increased requirement for more complex vascular access. ${ }^{16,17}$

The aim of this study was to compare outcome, patency, and complication rates of radiobasilic AVF (RBAVF) transposition in the forearm with the traditional one stage brachiobasilic AVF (BBAVF) transposition in the arm.

\section{Patients and methods:}

This study was conducted in the period from January 1, 2008 to December 31, 2010 to compare outcome, patency, and complication rates of RBAVF (group1) versus BBAVF (group2). Informed consent was obtained from all patients.

\section{Pre-operative assessment}

All patients with CRF admitted to Tanta University Hospitals planed for AVF during the period of study underwent Duplex scanning of the upper extremity arteries and veins as a standard investigation before operation. Clinical examination of the vessels of the upper limb, and measurement of blood pressure were done. CRF patients with the only basilic vein and no other available suitable superficial veins in both upper limbs are divided into two groups. Group1 includes those with suitable basilic vein in the arm and forearm and planned for RBAVF in the forearm. Group2 patients are those with suitable basilic vein only in the arm and sclerosed or unsuitable in the forearm and planned for the traditional one stage BBAVF in the arm as a comparative group. Patients with an active local and general infection and/or peripheral ischaemia of the upper extremities were excluded from this study.

\section{Operative procedure}

All operations were performed on an outpatient basis as same-day surgery using local infiltration anaethesia (1\% lidocaine) as one-stage procedures. No drains were used in the two groups.

In group 1 (RBAVF) preoperative vein mapping in the forearm was made by Duplex and confirmed clinically by placing the cuff of sphygmomanonometer in the upper part of the arm and elevating the pressure between the systole and diastole while the patient clenches and releases the ipsilateral hand several times Figure(1). The basilic vein in its posteromedial position in the forearm was dissected free from its surrounding tissue through multiple ${ }^{2-4}$ separate incisions and vein tributaries were dissected and ligated in continuity Figure(2). Mechanical vein dilatation was performed with saline Figure(3). The vein was transposed using a tunneler to a superficial tunnel in the volar aspect of the forearm Figure(4). The radial artery was exposed at the wrist to do distal RBAVF. When previous radiocephalic AVF was done the radial artery was exposed just proximal to the old operation to do midforearm RBAVF. The radial artery was dissected for $15 \mathrm{~mm}$ and arterial branches were dissected and ligated in continuity. The superficial branch of the radial nerve, which is sensory at this level, was identified and spared. Radial arteriotomy (5 to $7 \mathrm{~mm}$ ) was done after arterial clamping, and an end-to-side anastmosis Figure(5) was performed using 7/0 prolene sutures (Ethicon, Inc, Somerville, NJ). Before completion of the anastmosis, vascular dilators were used to dilate both the vein and artery to overcome spasm from vessel loops and manipulation. Wounds were closed using interrupted $3 / 0$ prolene sutures Figure(6,7).

In group 2 a brachiobasilic fistula was constructed in the arm. Briefly, a single long incision was made in the medial aspect of the arm rather than addition of a second separate incision for brachial artery exposure, as has been previously described by many authours. ${ }^{18,19}$ Exposure and dissection of the basilic vein from antecubital fossa to near the axilla was done. Tributaries were dissected and ligated Figure(8), and the vein was isolated and disconnected in the antecubital fossa Figure(9). The vein was then tunneled subcutaneously and anastmosed end to side to the brachial artery with $6 / 0$ prolene sutures (Ethicon, Inc, Somerville, NJ), in or just proximal to the antecubital fossa Figure(10). Wound was closed in layers; subcutaneous fat with vicryl $3 / 0$ and skin using interrupted $3 / 0$ prolene sutures. 


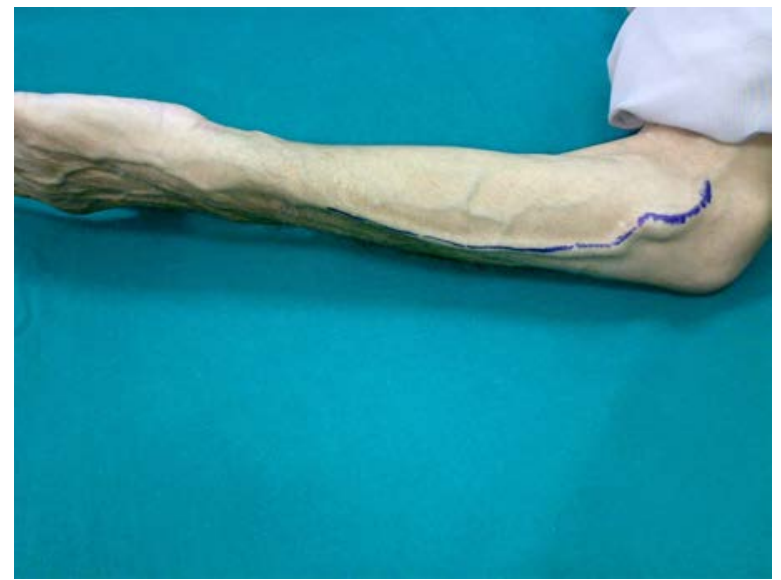

Figure (1): Preoperative mapping of the basilic vein in the forearm.

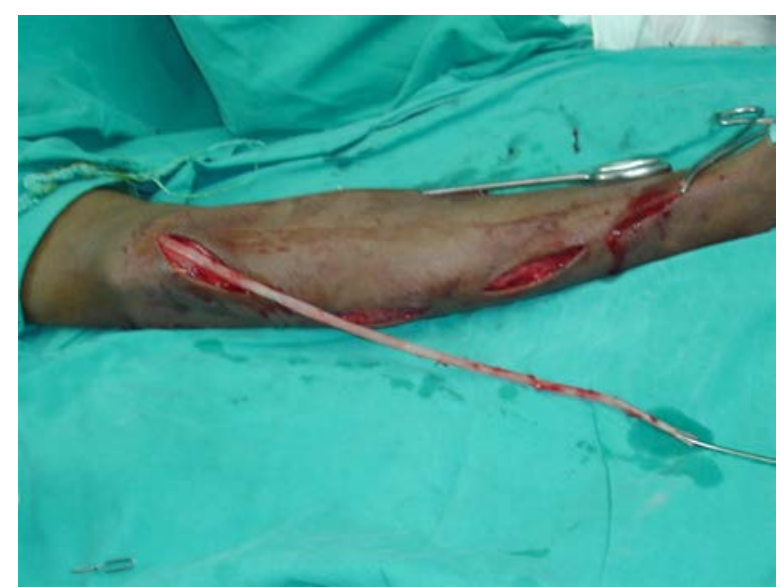

Figure (3): Dilatation of the basilic vein with saline.

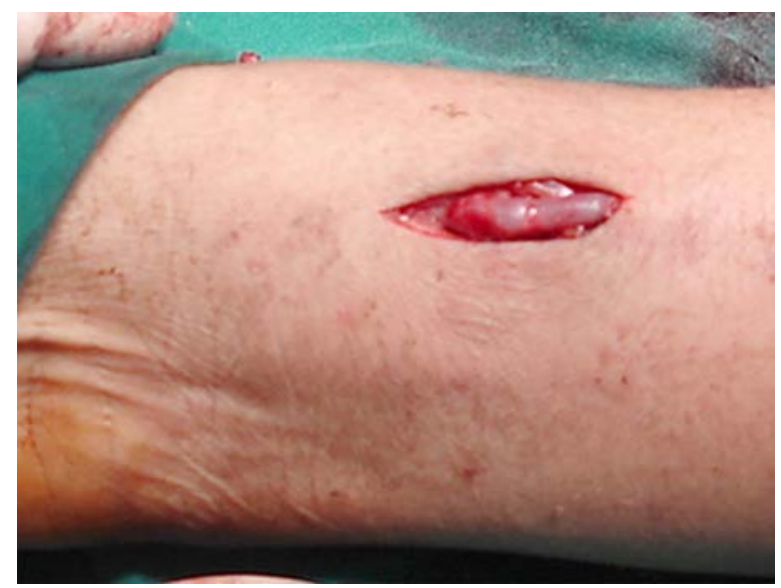

Figure (5): End-to-side RBAVF.

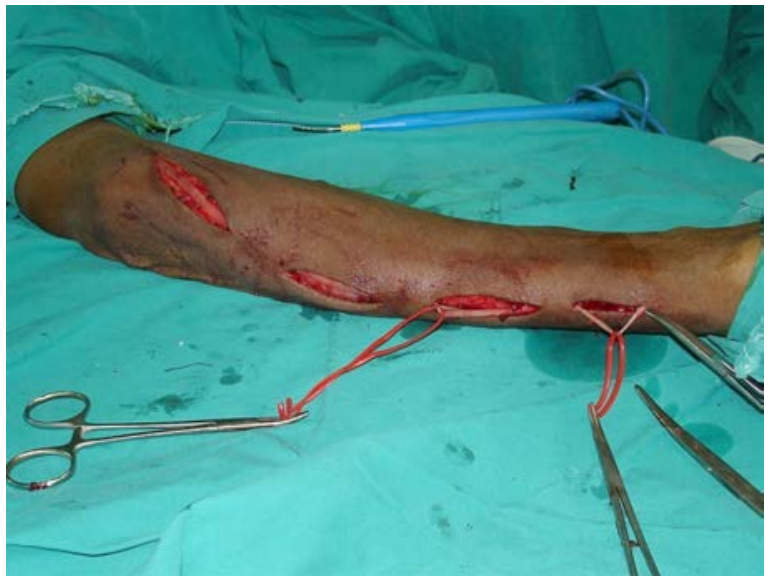

Figure (2): Dissection of the basilic vein and lgation of the tributaries through multiple separate incisions.

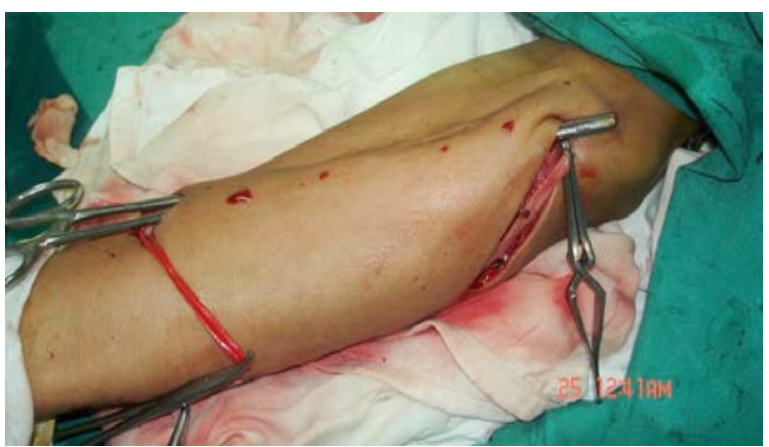

Figure (4): The tunneler in place to transpose the basilic vein in the volar aspect of the forearm.

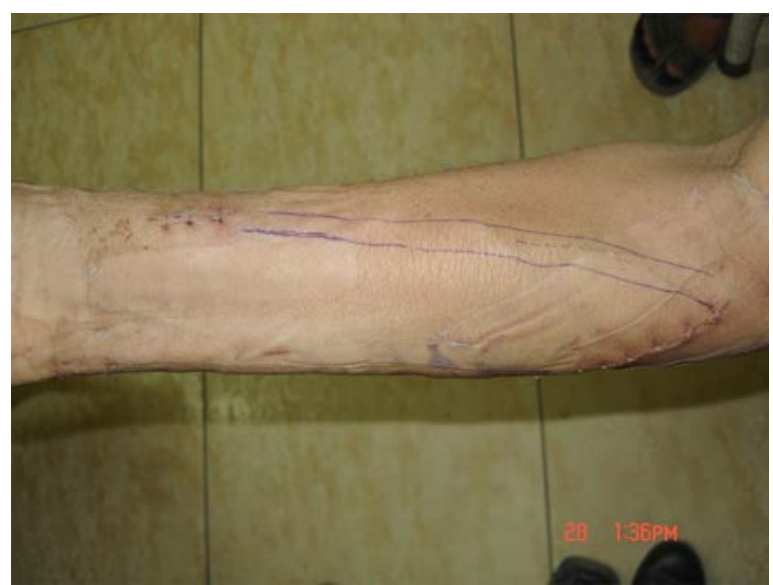

Figure (6): Early postoperative after transposition of the basilic vein and closure of the skin with prolene suture. 


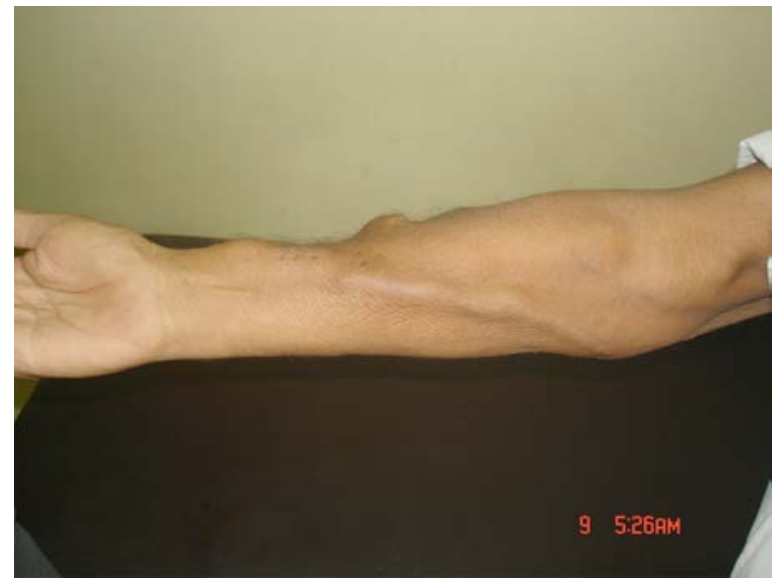

Figure (7): One month post operative with mature basilic vein in RBAVF.

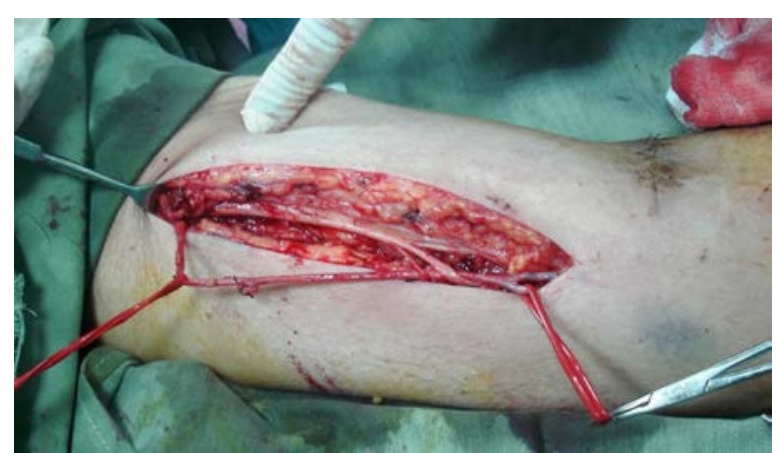

Figure (9): In group 2 complete dissection of the basilic vein in a patient with a previously failed brachiocephalic AVF.

\section{Follow-up:}

All patients were followed at 1, 3, 6, 9 \&12 months after operation. Following surgery, AVF were not used for at least one month allowing vein maturation and patients were reevaluated with Duplex examination, and the sites most suitable for needle insertion were marked on the skin. Early and late complications were recorded in both groups. A successful fistula was defined as a fistula that had been successfully needled for dialysis. The presence or absence of a thrill was not used to define technical success, because the simple presence of a thrill does not determine whether a fistula will mature to become usable or cannot be used for dialysis. ${ }^{20}$ Primary patency was defined as the percentages of all AVFs attempted that were still being used for dialysis and not required any intervention to maintain or re-establish patency at one year. ${ }^{14}$ Clinical criteria were used to detect thrombosis.

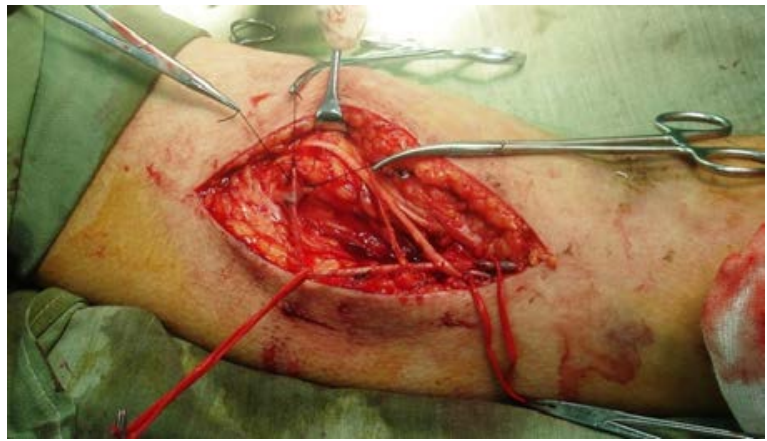

Figure (8): IN group 2 the basilic vein tributaries were dissected and ligated.

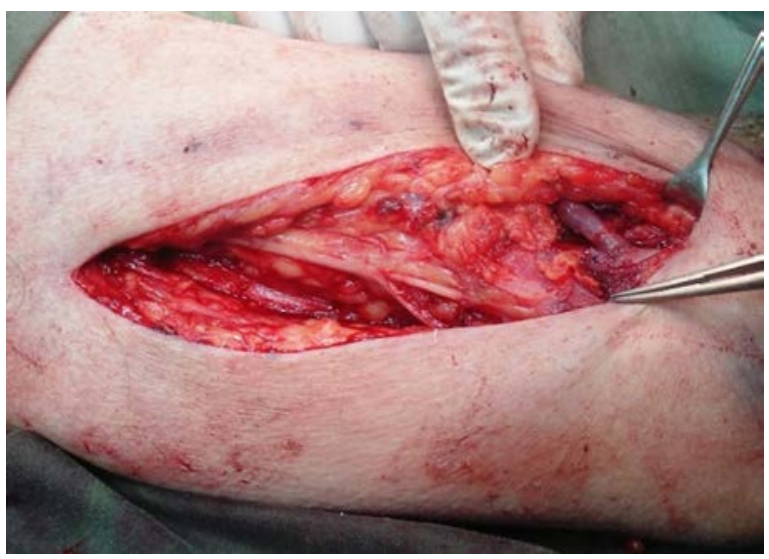

Figure (10): End-to-side BBAVF.

\section{Statistical analysis:}

Patient's demographic factors were compared by using the Mann-Whitney U test for continuous variables and $\mathrm{X}^{2}$ tests for categorical values. Primary fistula patency rate and patients' survival were analyzed using life table and Kaplan-Meier survival analysis. The two groups were compared by using log-rank test. Statistical analysis was performed by SPSS (version 12.0 for Windows). A P value of $<0.05$ was considered statistically significant.

\section{Results:}

Out of 512 CRF patients admitted to Tanta University Hospitals planed for AVF, the basilic vein was the only available one in 97 cases by preoperative Duplex examination. The basilic vein was suitable $(3 \mathrm{~mm}$ in diameter or more) in the forearm in only 23 cases $(23.71 \%)$. In the remaining 74 cases $(76.28 \%)$ 
it was suitable only in the arm and sclerosed in the forearm. In two out of 23 cases the basilic vein in the forearm was found intra-operatively to be unsuitable and in another case the radial artery was unsuitable in one patient and the basilic vein was used as a loop with the brachial artery in the forearm. All these three cases were excluded from our study. In the remaining 20 cases RBAVF in forearm was done (group1) in the form of distal AVF at wrist in 15 cases and midforearm AVF in 5 cases. In spite of preoperative evaluation, the basilic vein in the arm was found unsuitable for creation of a basilic vein transposition in the arm in four patients, and therefore, PTFE brachial-axillary arm loop AVF was created. One stage BBAVF in the arm was operated in 70 patients (group 2 ) as a comparative group. Basilic vein was used as a primary AVF in only 6 cases (30\%) in group 1 and in 16 cases (23\%) in group 2 and as a secondary or tertiary AVF in the rest of cases. In the follow up period two patients in BBAVF $(3 \%)$ died of complications of kidney failure with patent AVF during the follow-up period 6 and 11 months after operation. Therefore, 88 patients were eligible for analysis of survival curves (group 1=20). The two groups were well matched for age, sex, diabetes, hypotension and previous vascular access procedures. Patients' demographics are shown in Table(1).

The mean age of patients in group 1 was 42.3 years, with a range of 25 to 62 years, and included 13 men (65\%) and 7 women (35\%). The mean age of patients in group 2 was 51 years, with a range of 22 to 70 years, and included 39 men $(56 \%)$ and 31 women $(44 \%)$. The mean duration of the operation in group 1 was $74.6 \pm 13.18$ (70 - 90 minutes) and in group 2 was $176.9 \pm 30.56$ (85-240 minutes), $\mathrm{P}$ $<0.001$. In group 2 , the diameter of the basilic vein was greater (mean $4.3 \mathrm{~mm}$ ) than that in group1 (mean $3.2 \mathrm{~mm}$ ). The procedure was easier to the surgeon in group1 due to superficial vein in all cases when compared to deep vein in group 2 . The length of the vein to be used for needling in dialysis was longer in group 1 than in group 2 that made it easier for the nurses to insert two needles apart. The operation in 4 cases in group 2 was used for arterial needle only and no place for the venous needle which was inserted fortunately in another vein in the other limb with failed fistula and still patent vein.

\section{Patency rate:}

The immediate results were satisfactory in both groups, with a successful patency rate of 95\% in group 1 (1/20 AVF thrombosed) and $92.8 \%$ in group 2 (3/70 thrombosed \& $2 / 70$ insufficient flow). Primary 1-year patency was $75 \% \pm 6.43$ versus $70.14 \% \pm 8.94$ in group 1 and group 2 respectively (P 0.663 ). The summary of the RBAVFs/BBAVFs cumulative primary patency rates up to one year are listed in Table(2) and outlined in Figure(11).

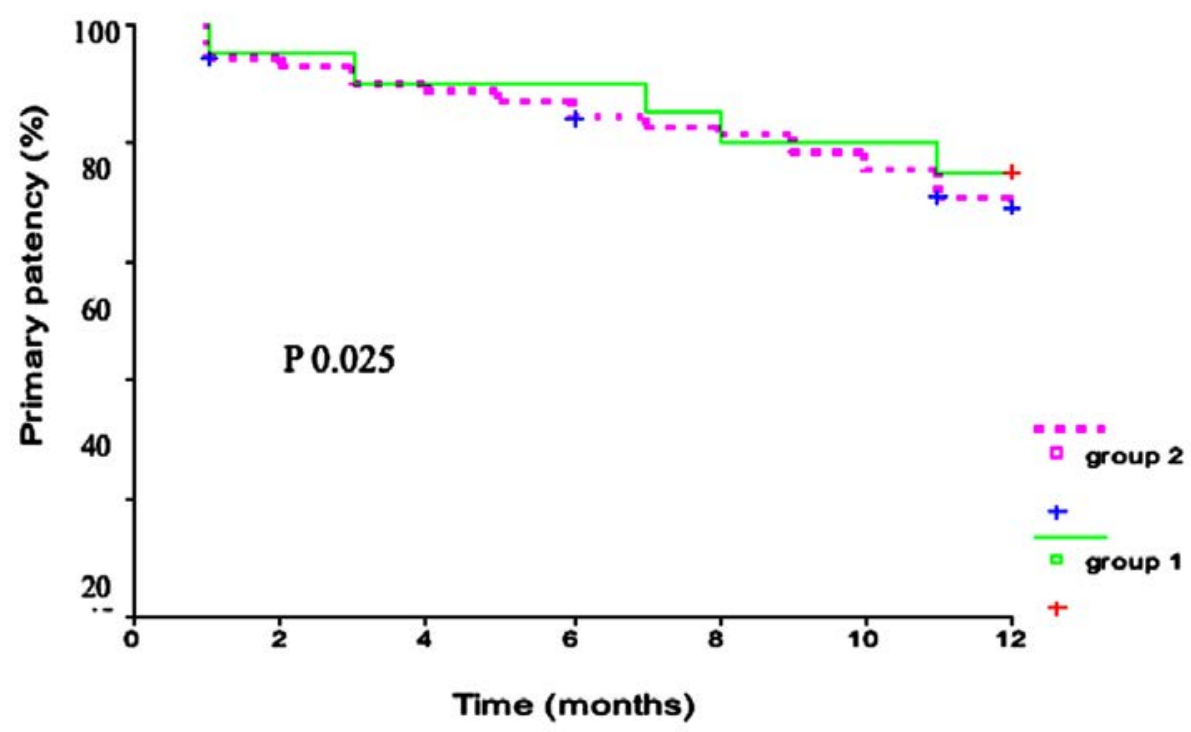

Figure (11): The patency rate in both groups during the first one year. 


\section{Complications and interventions:}

Postoperative complications recorded in group 1 and group $2(25 \% \& 67 \%)$ and their management during the period of study were shown in Table(3). These were in the form of infection and anastmosis disruption (BBAVF 1) that needed ligation, access thrombosis (BBAVF 15; RBAVF 3), Insufficient flow ( $<250 \mathrm{ml} / \mathrm{sec}$ flow by Duplex) (BBAVF 5; RBAVF 2), hematoma (BBAVF 7), and arterial steal syndrome (BBAVF 3) that was treated by distal revascularization with interval ligation (DRIL) operation. Limb oedema due to venous hypertension ( BBAVF 9) were recorded and needed angioplastic dilatation in three cases and axillary vein stent in one case. Venous aneurysm occurred in seven BBAVFs that needed surgical repair in two cases.

Multivariate analysis revealed that diabetes and hypotension increased the risk of failure. Also it revealed that venous hypertension and aneurysm increased with previous ipsilateral venous catheter.

Table (1): Patients demographics.

\begin{tabular}{|c|c|c|c|c|}
\hline & $\begin{array}{c}\text { Group (1) } \\
(n=20)\end{array}$ & $\begin{array}{c}\text { Group(2) } \\
(n=70)\end{array}$ & $X^{2}$ & $P$ value \\
\hline Male & $13(65 \%)$ & $39(53.8 \%)$ & 0.551 & 0.458 \\
\hline Mean age $(\mathrm{Y})$ & $42.3 \pm 8.32$ & $51 \pm 12.85$ & 2.87 & 0.007 \\
\hline Diabetes & $11(55 \%)$ & $25(35.7 \%)$ & 2.41 & 0.120 \\
\hline Hypotension & $5(25 \%)$ & $18(25.7 \%)$ & 0.874 & 0.241 \\
\hline \multicolumn{5}{|c|}{ *Previous limb procedures } \\
\hline \multicolumn{5}{|c|}{ *Central catheter in the same side } \\
\hline One time & $7(35 \%)$ & $38(54.2 \%)$ & 2.31 & 0.128 \\
\hline Two times & $5(25 \%)$ & $19(27.1 \%)$ & 0.041 & 0.848 \\
\hline \multicolumn{5}{|c|}{$* A V F$ in the same limb } \\
\hline Radiocephalic & $5(25 \%)$ & $49(70 \%)$ & 3.632 & 0.012 \\
\hline Brachiocephalic & $12(60 \%)$ & $19(27.1 \%)$ & 6.96 & 0.006 \\
\hline
\end{tabular}

Table (2): The patency rate in both groups during the first one year.

\begin{tabular}{|l|l|l|l|l|l|}
\hline Month & \multicolumn{1}{|c|}{$1^{\text {st }}$} & \multicolumn{1}{|c|}{$3^{\text {rd }}$} & $6^{\text {th }}$ & $9^{\text {th }}$ & $12^{\text {th }}$ \\
\hline Group 1 & $19 / 20$ & $18 / 20$ & $18 / 20$ & $16 / 20$ & $15 / 20$ \\
\hline Group 2 & $67 / 70$ & $62 / 70$ & $58 / 70$ & $54 / 70$ & $49 / 70$ \\
\hline
\end{tabular}


Table (3): Postoperative complications in both groups and their management.

\begin{tabular}{|l|c|c|c|c|}
\hline Complications & $\begin{array}{c}\text { Group1 } \\
(\mathrm{n}=20)\end{array}$ & $\begin{array}{c}\text { Group2 } \\
(\mathrm{n}=70)\end{array}$ & Interventions & P \\
\hline Infection and anastmosis disruption & ---------- & 1 & Ligation & - \\
\hline Seroma and hematoma & -------- & 7 & ----------- & - \\
\hline Insufficient flow & 2 & 5 & & 0.673 \\
\hline Access thrombosis & $3(15 \%)$ & $15(21.4 \%)$ & & 0.526 \\
\hline Steal syndrome & ------------ & 3 & DRIL & - \\
operation & \\
\hline Venous hypertension & ----------- & 9 & $\begin{array}{c}\text { Angioplastic } \\
\text { dilatation in 3 } \\
\text { and stent in 1 }\end{array}$ & - \\
\hline Venous aneurysm & & & $\begin{array}{c}\text { Surgical } \\
\text { repair } \\
\text { in two. }\end{array}$ & - \\
\hline Total & ------------ & 7 & 10 & 0.007 \\
\hline
\end{tabular}

\section{Discussion:}

As dialysis population becomes older (with various co-morbidity), the need for secondary and tertiary access, will grow. ${ }^{21}$ There is still no consensus which type of access to be preferred, when the basilic vein is the only available suitable vein for AVF, is to do RBAVF or BBAVF. Trials on this subject are lacking in the review of literatures. ${ }^{22}$ In our series, the RBAVF was shorter in time, easier in operation and more convenient in using for dialysis in comparison to the well settled BBAVF, this is owing to superficial basilic vein in the forearm and long segment available for needling even when used as midforearm fistula. In BBAVF, the segment of the vein is short and no place for the two needles for dialysis in four cases.

Arteriovenous fistula at the wrist has remained the procedure of choice for longterm chronic hemodialysis since its development by Brescia and Cimino in 1966. ${ }^{23}$ However, the early failure rate ( $<30$ days) remains a significant problem, affecting $24 \%$ of patients in a series reported by Palder. ${ }^{24}$ This may be due to technical problems at the anastmosis or stenotic lesions of the more proximal vein. ${ }^{25}$ The latter are caused by prior episodes of phlebitis and usually are not recognized preoperatively. The most common lesions occur in regions of previous thrombosis and recanalization; these are webs, strands, or areas of nondistensible vein with a thickened intimal surface. ${ }^{26}$ Beyond the first month, the long-term patency rate for radiocephalic fistulas is excellent. ${ }^{25}$ In our study, the immediate results were satisfactory with a patency rate of $95 \%$ in group 1 and $92.8 \%$ in group 2 . The explanation of excellent one month patency rate in both groups may be due to hidden posteromedial position of the basilic vein in the forearm or deep site in the arm away from injection and phlebitis and also due to preoperative use of Duplex examination.

In our study, the primary one year patency rate was higher $(75 \% \pm 6.43)$ in RBAVF than in BBAVF $(70.14 \% \pm 8.94)$ with no significant difference between both groups (P 0.663). Gormus et al. ${ }^{28}$ compared 10 cases RBAVF versus 10 cases BBAVF and found the patency rate at the end of 10 months were $80 \%$ versus $90 \%$ respectively. In another study the primary 1 year patency rate was $84 \%$ for vein transposition in the forearm. ${ }^{22}$ The one year 
patency rate of our study in BBAVF lies within the upper values of recorded literatures in the last 10 years. ${ }^{29-35}$

As regards to complication rates in both groups, it was significant higher in BBAVF $(67.14 \%)$ than RBAVF $(25 \%, \mathrm{P}=0.0007)$. There was insignificant high rate of AVF thrombosis in BBAVF than RBAVF (15\% Vs $21.4 \%, \mathrm{P}=0.526)$. Our work supported that transposed arteriovenous fistulas have significantly higher primary patency rate and are less likely to develop a significant infection than arteriovenous graft as previously reported by many authors. ${ }^{30,31}$

The incidence of venous aneurysm is significantly higher in BBAVF than in RBAVF (10\% to $0 \%$ ). Regarding the etiology of venous aneurysm in group 2, it could be attributed to the structural thin wall of basilic vein in the arm than in the forearm, high brachial artery flow than in radial artery and short segment of the vein used for needling in group 2 than in group 1 that make the vein week at the sites of punctures. Venous hypertension and arm oedema are more common in BBAVF (12.8\%) and no cases recorded in RBAVF. This may be due to extensive ligation of the tributaries of the basilic vein and previous venous catheter application in the same limb.

Thrombosis is the most common reason for early arteriovenous fistula loss. ${ }^{26}$ In the present study, multivariate analysis revealed that diabetes and hypotension increased the risk of fistula failure. It is well established that hemodynamic changes must occur to sustain, and increase flow through an arteriovenous fistula. Both antegrade and retrograde flow increase toward the low-resistance arteriovenous fistula which results in arterial dilatation. In diabetic patients they commonly display medial calcification, this may prevent such dilatation and increased fistula blood flow. 36

On the basis of the results of the present study, it could be concluded that RBAVF could be considered as an important option for vascular access and provide one year patency rate equivalent to that of BBAVF with significant lower complication rate. Therefore, RBAVF should be recommended in patients with CRF if the basilic vein is the only available suitable one.

\section{References:}

1- Miller A, Holzenbein TJ, Gottlieb MN, Sacks BA, Lavin PT, Goodman WS, et al: Strategies to increase the use of autogenous arteriovenous fistula in end-stage renal disease. Ann Vasc Surg 1997; 11: 397-405.

2- Xue JL, Ma JZ, Louis TA, Collins AJ: Forecast of the number of patients with end-stage renal disease in the United States to the year. J Am Soc Nephrol 2010; 12 (2001): 2753-2758.

3- Woo K, Farber A, Doros G, Killeen K, Kohanzadeh S: Evaluation of the efficacy of the transposed upper arm arteriovenous fistula: A single institutional review of 190 basilic and cephalic vein transposition procedures. J Vasc Surg 2007; 46(1): 9499. e3 and Presented at the 2005 Annual Meeting of the Western Vascular Society, Park City, Utah, Sept 24-27, 2005.

4- NKF-DOQI: Clinical practice guidelines for vascular access. Am J Kidney Dis 30S3 1997; 150-189.

5- NKF-K/DOQI: Clinical practice guidelines for vascular access: update 2000, Am J Kidney Dis 37(1Suppl) 2001; 137-179.

6- NKF-K/DOQI: Clinical practice guidelines for vascular access: update 2006, Am J Kidney Dis 48(1Suppl) 2006; 176-273.

7- Kheriakian GM, Roedersheimer LR, Arbaugh JJ, Newmark KJ, King LR: Comparison of autogenous fistula versus expanded polytetrafluoroethylene graft fistula for angioaccess in hemodialysis. Am J Surg 1986; 152: 238-243.

8- Coburn MC, Carney WI: Comparison of basilic vein and polytetrafluoroethylene for brachial arteriovenous fistula. J Vasc Surg 1994; 20: 896-904.

9- Gibson KD, Gillen DL, Caps MT, Kohler TR, Sherrard DJ, Stechman-Breen CO: Vascular access survival and incidence of revisions: a comparison of prosthetic grafts, simple autogenous fistulas, and venous transposition fistulas from the United States Renal Data System Dialysis Morbidity and Mortality Study. J Vasc Surg 2001; 34: 694-700.

10-Pisoni RL, Young EW, Dykstra DM, Greenwood RN, Hecking E, Gillespie B, et al: Vascular access use in Europe and the United States: Results from the DOPPS. 
Kidney Int 2002; 61: 305-316.

11- Kalman PG, Pope M, Bhola C, Richardson $\mathrm{R}$, Sniderman KW: A practical approach to vascular access for hemodialysis and predictors of success. J Vasc Surg 1999; 30: 727-733

12-Ascher E, Gade P, Hingorani A, et al: Changes in the practice of angioaccess surgery: Impact of dialysis outcomes and quality initiative recommendations. J Vasc Surg 2000; 31: 84-90.

13-Pate ST, Hughes J, Mills JL, Sr: Failure of arteriovenous fistula maturation: An unintended consequence of exceeding dialysis outcome quality initiative guidelines for hemodialysis access. J Vasc Surg 2003; 38(3): 439-445

14-Sidawy AN, Gray R, Besarab A, Henry M, Ascher E, Silva M, et al: Recommended standards for reports dealing with arteriovenous hemodialysis access. J Vasc Surg 2002; 35(3): 603-610.

15-MalovrhM: Native arteriovenous fistula: Preoperative evaluation. Am J Kidney Dis 2002; 39: 1218-1225.

16-Murphy GJ, White SA, Nicholson ML: Vascular access for haemodialysis. $\mathrm{Br} \mathrm{J}$ Surg 2000; 87: 1300-1315.

17-Hernan A, Bazan, Schanzer H: Transposition of the brachial vein: A new source for autologous arteriovenous fistulas. J Vasc Surg 2005; 41(6): 1080-1081.

18-Dagher F, Gelber R, Ramos E, SadlerJ: The use of basilic vein and brachial artery as an AV fistula for long-term haemodialysis. J Surg Res 1976; 20: 373376.

19-Rivers SP, Scher LA, Sheehan E, Lynn R, Veith FJ: Basilic vein transposition: an underused autologous alternative to prosthetic dialysis angioaccess. J Vasc Surg 1993; 18: 391-397.

20-Won T, Jang JW, Lee S, Han JJ, Park YS, Ahn JH: Effect of intraoperative blood flow on the early patency of radiocephalic fistulas. Ann Vasc Surg 2000; 14: 468-472.

21-Butterworth PC, Doughman TM, Wheatley TJ, Nicholson ML: Arteriovenous šstula using transposed basilic vein. Br J Surg 1998; 85: 653-654.
22-Silva MB, Hobson RW, Peter J Pappas PJ, Paul B, Haser PB, Clifford T, Araki CT, Mark C, Goldberg MC, Jamil Z, Padberg FT: Vein transposition in the forearm for autogenous hemodialysis access. $J$ Vascular Surgery 1997; 26(6): 981-988.

23-Brescia MJ, Cimino JE, Appel H, Hurwich BJ: Chronic hemodialysis using venipuncture and a surgically created arteriovenous fistula. $N$ Engl J Med 275 1966; 1089-1092.

24-Palder SB, Kirkman RL, Whittemore AD, Hakim RM, Lazarus JM, Tilney NL: Vascular access for hemodialysis, patency rates and results of revision. Ann Surg 1985; 202: 235-239.

25-Ryan JJ, Dennis MJS: Radiocephalic fistula in vascular access. Br J Surg 1990; 77: 1321-1322.

26-Lazarides MK, Staramos DN, Tzilalis VD, Konstantinos E, Simopoulos KE, Dayantas JN: Evoked thrill: A simple intraoperative maneuver predicts early patency of arteriovenous fistulas. J Vasc Surg 1998; 27(4): 750-752.

28-Gormus N, Ozergin U, Durgut K, Yuksek T, Solak H: Comparison of autologous basilic vein transpositions between forearm and upper arm regions. Ann Vasc Surg 2003; 17(5): 521-526.

29-Hossny A: Brachiobasilic arteriovenous fistula: Different surgical techniques and their effect son fistula patency and dialysisrelated complications. J Vasc Surg 2003; 37: 821-826.

30-Dix FP, Khan Y, Al-Khaffaf H: The brachial artery-basilic vein arterio-venous fistula in vascular access for haemodialysi: A review paper. European Journal of Vascular and Endovascular Surgery 2006; 31(1): 70-79.

31- Weale AR, Bevis P, Neary WD, Lear PA, Mitche DC: Arteriovenous šstulas and prosthetic brachioaxillary Access grafts for vascular access for hemodialysis. J Vasc Surg 2007; 46: 997-1004.

32- Keuter XH, Kessels AG, De Smet AA, van der Sande FM, Tordoir HM: A randomized multicenter study of the outcome of brachial-basilic arteriovenous šstula and prosthetic brachial-antecubital forearm loop as vascular access for 
hemodialysis. J Vasc Surg 2008; 47: 395401.

33-Harper SJF, Goncalves I, DoughmanT, Nicholson ML: Arteriovenous fistula formation using transposed basilic vein: Extensive single centre experience. European Journal of Vascular and Endovascular Surgery 2008; 36(2): 237241.

34- Koksoy C, Demirci RK, Balci D, Solak T, Köse SK: Brachiobasilic versus brachiocephalic arteriovenous fistula: A prospective randomized study. J Vasc Surg 2009; 49(1): 171-177.
35- Korkut AK, Kosem M: Superficialization of the basilic vein technique in brachiobasilic arteriovenous fistula: Surgical experience of 350 cases during 4 years period. Annals of Vascular Surgery 2010; 24(6): 762-767.

36-Hakaim AG, Nalbandian M, Scott T: Superior maturation and patency of primary brachiocephalic and transposed basilic vein arteriovenous fistulae in patients with diabetes. J Vasc Surg 1998; 27: 154-157. 